\title{
Exploración de la otredad en la filosofía contemporánea
}

\section{Javier Alegre ${ }^{*}$}

La filosofía contemporánea, si bien es diversa y multifacética, otorga a la razón características diferentes de las que se le atribuyeron en la modernidad; mediante el proceso denominado deflación de la razón se reconoce a ésta como producto de una construcción cultural, ya no bajo parámetros absolutos y necesarios. La razón entendida de modo unívoco y las teorías filosóficas universales retrocedieron y cedieron lugar a diversas filosofías contextualizadas, a la vez que otros tipos de racionalidad irrumpieron en los planteos teóricos reclamando validez y legitimidad propias. ${ }^{1}$ Al mismo tiempo que se producía este descentramiento de la razón, Europa intensificaba su contacto con las colonias y comenzaba a tomar un conocimiento pormenorizado de formaciones socio-culturales muy distintas a la de la tradición occidental. Este contacto fluido con, y la necesidad de dominio de, este otro cultural fue motivo principal de la constitución de la antropología cultural como disciplina científica sobre fines del siglo XIX.

En relación con esto, en el presente trabajo nos proponemos explorar la existencia, aunque sea implícita, y la importancia de la noción de otredad, en cuanto categoría de pensamiento, en los orígenes de la filosofía contemporánea, más precisamente su presencia en dos autores fundamentales del siglo XIX: Karl Marx y Friedrich Nietzsche. Vale aclarar que Paul Ricoeur, en un estudio ya clásico, ${ }^{2}$ ve a Marx y Nietzsche -junto con Freud- como "maestros de la sospecha" que desconfían de la ilusión moderna de que la conciencia de sí y el sujeto sean las entidades fundantes de la realidad (ambos denuncian "la mentira de la conciencia, la conciencia como mentira"); coincidiendo en rasgos generales con este planteo, lo que intentamos hacer aquí es profundizar en la línea de cuáles son los elementos teóricos presentes en ambos autores que se oponen a la tradición filosófica y las estructuras sociales occidentales -no tanto a la conciencia y sujeto- y que, por lo mismo, son pasibles de ser considerados como otredades impugnadoras de dichas tradiciones y estructuras.

Con la finalidad de alcanzar el objetivo propuesto, la exposición pasa por distintos momentos: a) despliegue sintético del concepto de otredad en el campo antropológico y su relación con las condiciones del contexto social y filosófico en los inicios de la contemporaneidad; b) análisis de aquellos conceptos de Marx que puedan ponerse en relación con la temática de la otredad; c) igual tarea con determinados conceptos de Nietzsche; y d) evaluación de la posible pertinencia de la noción de otredad en estos dos autores para explicar algunas transformaciones del pensamiento contemporáneo.

\section{Concepción de otredad y características del nosotros decimonónico}

La otredad es una categoría antropológica que no puede delimitarse otorgando una simple definición, ya que representa tanto un concepto como una problemática no resuelta. Para abordarla conviene exponer su desarrollo, las más destacadas apropiaciones hechas por distintas corrientes antropológicas y, finalmente, arriesgar la demarca-

\footnotetext{
*E-mail: taton@gmx.net

*E-mail: nietajj@yahoo.com.ar

${ }^{1}$ Cfr.: Habermas, Jürgen. Pensamiento post-metafísico. Trad. Manuel Jiménez Redondo. Taurus, Madrid, 1990.

${ }^{2}$ Ricoeur, Paul. Le conflit des interprétation. Éditions du Seuil, París, 1969.
} 
ción-construcción del modo que nos resulta más pertinente, ya que lo otro se muestra como el resultado siempre inconcluso de cierta violencia o sometimiento ejercidos sobre lo que nos resulta extraño y pretendemos conocer e interpretar. ${ }^{3}$

La otredad cultural consiste, en principio, en todo aquello que difiere del nosotros cultural, que no es propio de los parámetros sociales a los cuales se está habituado. Sin embargo, como es de esperar, no existe un único modo de concebir la otredad, ésta ha sido entendida de manera diferente dependiendo de las corrientes teóricas predominantes en las distintas épocas, las cuales presentan no sólo diversas interpretaciones de la otredad como conjunto de hechos empíricos o datos objetivos, sino que, fundamentalmente, también constituyen construcciones heterogéneas de imágenes y modelos del otro cultural. Pueden distinguirse tres momentos constitutivos de la otredad de acuerdo con los procesos históricos acaecidos y las teorías preponderantes que influyen decisivamente en la definición y explicación del quehacer antropológico en cada período: a) a fines del siglo XIX, b) entre Guerras Mundiales, y c) luego de la II Guerra Mundial. ${ }^{4}$

En el primer momento, la división económica del mundo entre metrópolis (donde se desarrollan las industrias) y colonias (donde se colocan productos y se obtienen materias primas) va acompañada de la dicotomía en el plano de las ciencias sociales entre sociología (disciplina del nosotros cultural, propia de la metrópolis) y la antropología (disciplina de los otros coloniales, de los pueblos que están alejados geográfica e históricamente y que practican un estilo de vida distinto del europeo y norteamericano). En este período, predomina el evolucionismo de Lewis Morgan y Edward Tylor, que asocia la cultura a la acumulación progresiva de manifestaciones específicas y, de acuerdo con parámetros positivistas, sostiene que todas las culturas pasan por los mismos estadios en el curso de su desarrollo: primero salvajismo, luego barbarie y finalmente civilización. El evolucionismo explica la pluralidad de culturas por medio de la concreción, o no, de niveles más avanzados y la otredad cultural es contemplada como aquello diferente a Occidente, el cual es utilizado como parámetro válido para distinguir el grado de progreso de cualquier otra formación cultural. El otro es comprendido en una relación de inferioridad cultural, la diferencia siempre es peyorativa, marca la ausencia de los rasgos europeos que debían surgir para lograr el máximo estadio evolutivo (la civilización).

En el segundo momento, de entreguerras, las fuertes críticas al carácter etnocéntrico del método comparativo evolucionista, debido a que convertía la propia cultura en el criterio exclusivo para interpretar los comportamientos de otros grupos o sociedades, configuran las bases para el surgimiento del paradigma funcionalista. La antropología funcionalista reniega de los intentos por explicar el desarrollo total de la humanidad o construir grandes escalas del progreso y se centra en estudiar el modo en que las sociedades particulares resuelven sus necesidades a través de la cultura. Bronislaw Malinowski considera que cada cultura satisface los requerimientos básicos de un grupo con una configuración siempre distinta y entendible sólo bajo sus propios términos; por lo

\footnotetext{
${ }^{3}$ Michel Foucault señala que interpretar es una acción que intenta apropiarse "mediante violencia o subrepticiamente, de un sistema de reglas que no tiene en sí mismo significación esencial, e imponerle una dirección, plegarlo a una voluntad, hacerlo entrar en otro juego, y someterlo a reglas segundas...". Foucault, Michel. Microfísica del Poder. Trad. Julia Varela y Fernando Alvarez-Uría. Madrid, La Piqueta, 1992, pp. 16-17.

${ }^{4}$ Cfr.: Boivin, M., Rosato, A. y Arribas, V. Constructores de otredad. Eudeba, Bs. As., 1998; Mancusi, M. y Faccio, C. Antropología Social. Docencia, Bs. As., 2000; Tzvetan, T. El problema del otro. Trad. Flora Burlá. Siglo XXI, México, 1995; y Tzvetan, T. Nosotros y los otros. Trad. Martí Mur Ubasart. Siglo XXI, México, 1991.
} 
tanto aquí el otro cultural no se determina por ser evolucionado o retrasado, deja de ser comprendido como lo diferente (con sus connotaciones despectivas y etnocentristas) y comienza a interpretarse como lo diverso. La otredad es simplemente aquello diverso/ajeno a nuestra cultura, que debe ser pensado bajo sus propios parámetros.

En tanto que en el tercer y último período señalado, tras la II Guerra Mundial, la colonización entra en su etapa final y se extienden los movimientos de independencia y nacionalización, a la par que se produce una occidentalización del mundo ya que la influencia cultural de Occidente transforma y asimila gran parte de las culturas a escala global. En el campo antropológico surgen críticas hacia el funcionalismo por no haber tomado debida cuenta de la situación histórica en que las culturas particulares entraban en contacto en el sistema colonialista, básicamente por no hacer suficiente hincapié en las relaciones de asimetría, explotación y violencia que surgen de dicho cruce. Culturas y sociedades ya no son entendidas como instancias separadas por un hiato insalvable que deban ser estudiadas por disciplinas diferentes; tanto la sociología como la antropología comienzan a compartir su objeto de estudio y sus técnicas; por lo que ahora no sólo los problemas de desigualdad presentes entre diversas sociedades, sino también en el seno de toda sociedad o cultura sirven para comprender y construir la otredad. En este contexto, el otro se configura como producto de las diferentes desigualdades económicas, culturales, científicas, etc. que entrecruzan la vida social y se manifiestan claramente a lo largo de la historia tanto entre culturas muy distantes en cuanto a geografía y acervo cultural como entre los grupos sociales que cohabitan un mismo espacio y hasta comparten una tradición cultural similar. La otredad toma el rostro (múltiple) de todos aquellos grupos que poseen un capital cultural que no coincide con el que es distintivo de la cultura hegemónica y que es menospreciado y/o sometido por ésta, la cual se convierte en predominante gracias al usufructo de las desigualdades antedichas y ejerce su influencia y superioridad principalmente mediante estrategias de dominación simbólica aquende y allende. ${ }^{5}$

La concepción de otredad que tomamos como base y utilizamos en el presente escrito es deudora de esta tercera postura. Lo otro no sólo se muestra irreducible, sino que también desafía y se opone al modelo imperante en cualquier ámbito en un determinado momento. La otredad es el modo en que el nosotros trata de explicarse lo que no es como si mismo, por ello es una entelequia constituida por este nosotros, si bien tiene existencia independiente de él. En el ámbito del pensamiento, la otredad refiere a las estrategias conceptuales por medio de las cuales un colectivo de investigadores otorga significado a todo lo que difiere de las prácticas y sistemas de ideas que priman en su propia cultura. En tanto que en el campo filosófico en específico, entenderemos lo otro como aquello que actúa como límite o contraposición de las aspiraciones y autoconcepción del principal concepto que fundamenta la modernidad: la razón, y también del grupo social que se erige como fiel representante de esta racionalidad en el siglo XIX: la burguesía.

Para comprender el significado de la otredad en un período determinado es necesario incluir las características y los mecanismos de exclusión y dominio propios del nosotros epocal, sin ellos es imposible entender por qué lo otro es constituido como tal. Pues bien, en el siglo XIX lo propio de Occidente en el plano filosófico está representa-

\footnotetext{
${ }^{5}$ Las nociones de capital cultural, relaciones de campo, hegemonía, estrategias de dominio, etc. están en directa relación con los análisis de Pierre Bourdieu. Ver especialmente: Esquisse d'une téorie de la pratique. Éditions du Seuil, París, 2000 (1º: 1972) - Questions de sociologie. Éditions de Minuit, París, 1980 Langage et pouvoir symbolique. Éditions Fayard, París, 2001.
} 
do por el legado de la modernidad de neto corte iluminista y con continuación en el positivismo, mientras que en el plano socio-económico tiene como expresión el ascenso de la burguesía y la instauración del capitalismo industrial. Existen evidentes interrelaciones entre las características de ambos planos y procesos, que expondremos en forma muy sucinta.

A modo de breve recordatorio, queremos rescatar aquí que el surgimiento de la cosmovisión moderna está asociada con el ascenso de la clase burguesa y sus correspondientes discursos ideológicos, también con la promoción de los movimientos sociales que desembocaron en las distintas revoluciones políticas y la constitución de los estados nacionales y con los avances técnicos que posibilitaron las revoluciones industriales y la matematización de la naturaleza. Las principales características del legado moderno que nos interesan retomar están en relación con: a) exaltación de una razón unitaria, racionalidad que es eje de toda certeza teórica y práctica y es capaz de actuar como reguladora de las relaciones sociales; b) confianza en que el género humano iría logrando una gradual emancipación mediante el desarrollo conjunto de la razón y la libertad; c) fe en que la historia está orientada teleológicamente hacia el progreso indefinido de la humanidad y que este progreso conduciría a la unificación, la independencia y el esclarecimiento racional; d) enaltecimiento de la metodología, racionalidad y sistematización científicas; e) afirmación de la correspondencia entre realidad y conocimiento, entre ser y verdad; f) hincapié en la autonomía moral, política y gnoseológica de los individuos; g) predominio del sujeto y la conciencia en el campo de la filosofía, en cuanto orígenes del pensamiento y ámbitos propio de estudio.

En el ámbito social, el siglo XIX europeo puede caracterizarse como el proceso de "creación de un mundo único bajo la hegemonía capitalista (sistema económico característico de la burguesía)". 6 Los avances científico-técnicos y el desarrollo económico producidos por las Revoluciones Industriales, al calor del auge burgués, introducen grandes transformaciones sociales y políticos. Las migraciones masivas de las zonas rurales a las urbanas, el surgimiento de las metrópolis multitudinarias, la conformación de la clase obrera industrial urbana y las condiciones inhumanas de trabajo son algunos de sus rasgos sobresalientes. El avance económico sin precedentes prefigura un cambio en el sistema económico que ya no se conduce en su mayoría por el ciclo agrario dependiente de las vicisitudes de las cosechas y el ganado, sino por el régimen comercial organizado de manera más compleja por la producción en serie y las fluctuaciones del mercado. La influencia de la burguesía se hace notar en política: muchos gobiernos abandonan instancias proteccionistas en el mercado, se suceden revoluciones y el auge de la economía y los altos índices de producción provocan el afianzamiento de las ideas y valores burgueses y de las instituciones políticas liberales. De este modo, la confianza en el progreso, el optimismo social y los grandes desarrollos tecnológicos, científicos y económicos conviven en el siglo XIX con un presente opacado por las miserias, violencias y epidemias que generan las condiciones de hacinamiento propias de los nuevos grandes centros urbanos.

\section{Marx y la otredad}

Consideramos que en el pensamiento de Marx puede entreverse la existencia de una otredad enfrentada a las situaciones dominantes tanto en el plano social como en el

\footnotetext{
${ }^{6}$ Hobsbawn, Eric. La era del capital, 1848-1875. Trad. Fluixá García y Carlo Caranci. Crítica, Bs As, 2001, p. 342.
} 
filosófico, producida justamente por las novedosas condiciones impuestas por el capitalismo industrial del XIX. En lo social, el proletariado se presenta con claridad como la parte opuesta, sometida y necesariamente impugnadora de las promesas del nosotros burgués que intenta imponer valoraciones, visiones e instituciones forjadas a imagen y semejanza propia. En lo filosófico, la concepción de filosofía marxista indudablemente pone en cuestión la forma clásica tradicional de llevar a cabo esta disciplina y la finalidad que clásicamente se le ha otorgado.

Si bien ambas otredades se encuentran estrechamente relacionadas, las desarrollamos a continuación en apartados separados para tratar de ganar en precisión.

\subsection{Otredad social: proletariado y alienación}

En el período que nos ocupa aquí, siglo XIX, los avances tecnológicos y las grandes ganancias emanados de la producción industrial generaron una división del trabajo y especialización infinitamente superiores a las que se habían dado hasta entonces, a la vez que dieron origen a una estructuración social inédita, en la que adquirieron relevancia determinante la burguesía y el proletariado, que se convierten en los principales actores de los procesos sociales ocurridos durante la era contemporánea. El proletariado es el antagonista complementario de la burguesía, ${ }^{7}$ ambos entran necesariamente en relación para intercambiar dinero por fuerza de trabajo con el fin de alcanzar sus objetivos: los burgueses, incrementar sus riquezas; los proletarios, ganar lo suficiente para subsistir.

Para que el libre intercambio de dinero por fuerza de trabajo suceda, previamente debe darse un proceso de cosificación del trabajo mediante el cual la fuerza laboral que es abstracta se transforma en una cosa mensurable y cuantificable según parámetros fijos (horas, puesto, producción, etc.) y el trabajador es reducido a depositario de esa cosa. Esta doble mutación se da con el fin de que en el mercado puedan entrar libremente en transacción los burgueses, que cuentan con el capital y los medios de producción, y los obreros, que cuentan solamente con su fuerza de trabajo. Marx señala que esta relación no es ecuánime ya que entre lo que ambos grupos tienen para ofrecer existe una gran diferencia: lo que poseen los capitalistas puede acumularse sin deteriorarse y ellos pueden sobrevivir tranquilamente sin negociarlo, en tanto que la fuerza de trabajo de los obreros no es acumulable y morirían de hambre si no la pusieran en venta. Si el capital no se comercializa, se guarda como stock; si el trabajo no se vende, se destruye, no llega a existir. La libertad con la que se cree entablar las relaciones en el mundo laboral es ficticia, los burgueses no están constreñidos a hacerlo -únicamente lo hacen por su deseos de ganancias-, en cambio los obreros sí están obligados porque de lo contrario perecerían; de allí que los primeros puedan fijar los precios de los salarios según sus propios parámetros y a los segundos sólo les quede acatar: "los trabajadores están obliga-

\footnotetext{
${ }^{7}$ Para precisar en qué consisten sendas clases y no generar malentendidos, conviene recurrir a la nota agregada por Engels en la edición de 1888 del Manifiesto Comunista, en donde presenta una definición clara y sintética: "por burguesía se comprende a la clase de los capitalistas modernos, propietarios de los medios de producción social, que emplean el trabajo asalariado. Por proletarios se comprende a la clase de los trabajos asalariados modernos, que, privados de medios de producción propios, se ven obligados a vender su fuerza de trabajo para poder existir". Marx, Karl y Engels, Friedrich. Manifiesto del Partido Comunista. Ediciones en Lenguas Extranjeras, Beijing (China), 1991, p. 32.
} 
dos a ofrecer su persona y su fuerza por el precio que quiera concedérseles. Cuanto más largo, penoso y desagradable sea el trabajo que se les asigna, tanto menos se les paga". ${ }^{8}$

Debido a esta situación asimétrica es que las condiciones laborales que se ven obligados a aceptar los obreros sean francamente inhumanas. ${ }^{9}$ Marx observa que el trabajo, en el modo en que es realizado en su época, pierde el carácter de expresión de las facultades del hombre ya que, básicamente, el trabajo y sus productos adquieren una forma de ser antagónica a la existencia del trabajador. El trabajo no es satisfactorio, en el sentido de que no responde a las necesidades genéricas sino que únicamente responde a las ansias de ganancias de los burgueses. La producción no existe para el desarrollo y satisfacción del obrero, al contrario, éste existe para aumentar la producción y las riquezas de los capitalistas: "el obrero es más pobre cuanta más riqueza produce, cuanto más crece su producción en potencia y en volumen. El trabajador se convierte en una mercancía tanto más barata cuantas más mercancías produce. La desvalorización del mundo humano crece en razón directa de la valorización del mundo de las cosas". ${ }^{10}$ El fin supremo de la vida son los valores económicos (ganancia, ahorro, etc.) y los valores humanos (de realización genérica) pasan a segundo plano. El trabajador asalariado deja de ser un fin en sí mismo y se vuelve un medio para el aumento de los bienes materiales, es explotado, recibe muchísimo menos de lo que debería ya que no se le paga por lo que produce, sino de acuerdo con el mínimo necesario para que renueve su fuerza de trabajo y reproduzca su prole -de modo de asegurar la existencia de mano de obra barata en el futuro-. Su salario está en relación solamente con el costo mínimo de la producción de la mercancía, pero no con las ganancias que genera, el capitalista "revierte al obrero la parte más pequeña e imprescindible del producto; sólo aquella que es necesaria para que él exista no como hombre, sino como obrero, para que perpetúe no la humanidad, sino la clase esclava de los obreros. (...) el obrero, muy lejos de poder comprarlo todo, tiene que venderse a sí mismo y a su humanidad". 11

Marx observa que las condiciones en que se desarrolla el trabajo vuelven imposible la concreción de las características que hacen de él una instancia auténticamente humana; en el industrialismo del siglo XIX el trabajo no es una actividad libre, voluntaria, conciente ni creativa. Y si el hombre no se realiza en su trabajo entonces no es un ser humano cabal, sino que deviene en un ser parcializado, mutilado, truncado, se convierte en otro tipo de individuo, un ser alienado. El trabajo bajo las formas del capitalismo es, por lo tanto, productor de alienación; pero si bien ésta surge en el ámbito laboral no se reduce a permanecer en él, es un fenómeno que luego se traslada a toda la vida

\footnotetext{
${ }^{8}$ Marx, Karl. Manuscritos: economía y filosofía. Trad. Francisco Rubio Llorente. Altaya, Barcelona, 1997, p. 71.

${ }^{9}$ La jornada laboral se extendía generalmente entre 12 y 16 horas diarias, las tareas que debían realizar eran repetitivas hasta el hartazgo, mecanizantes y cumplidas muchas veces sin luz solar, con escasa ventilación, en mala posición corporal, etc., los niños y jóvenes eran obligados a trabajar desde edad muy temprana, la paga era muy baja (apenas alcanzaba para que el grupo familiar sobrevivera) y los obreros carececían de servicios de salud y jubilación. El debilitamiento corporal y la extenuación provocadas por las largas jornadas de trabajo, junto con la falta de higiene adecuada y de agua potable y la diseminación de enfermedades epidémicas, reducía notablemente la esperanza de vida de los obreros.

${ }^{10}$ Marx, Karl. Manuscritos: economía y filosofía. Op. cit., p. 106.

${ }^{11}$ Ibíd. p. 61. El capital, según Marx, consiste justamente en trabajo acumulado pues, dada una cantidad determinada de materias primas y medios de producción, la fuerza de trabajo es la única que puede generar nuevos bienes y riquezas. Para aumentar el capital más rápidamente, se acrecienta la división del trabajo y la mecanización y monotonía de las actividades laborales, lo que a su vez conlleva la disminución del tiempo aprendizaje o capacitación necesarios para desarrollar las tareas y, por consiguiente, la baja de lo que se paga a quien las realiza.
} 
humana. ${ }^{12}$ La alienación o enajenación refiere a volcar fuera de sí lo que es más propio, a que se pierda y vuelva extraño lo que es específicamente humano. ${ }^{13}$ Consiste en que el hombre no se experimenta a sí mismo como el factor activo en la construcción y captación del mundo, sino que se siente un ser pasivo al que sólo le cabe sufrir lo que el destino le depare; lo convierte en un ser incapaz de cambiar su vida, de ser motor de transformaciones, de construir historia y lo conduce a un estado permanente de embotamiento y extrañamiento. La naturaleza, el hombre y el género humano todo permanecen ajenos al ser humano, dejan de ser un reflejo de sus capacidades, un espejo en cual reconoce su humanidad, y los vive como algo dado, ya fijado, independiente de su acción y de su voluntad. El mundo natural y social se le vuelven extraños. Esta situación le impide desarrollar sus potencialidades y habilidades genéricas, a la vez que lo reduce a un estado semejante al de los animales en el que ni la libertad ni la felicidad están a su alcance.

Se hace evidente que en la visión marxista las condiciones de vida del proletariado se presentan como una clara negación de la civilización europea, la cual ve en su propio desarrollo la consumación de la razón y la libertad, por oposición a los pueblos primitivos, bárbaros, no civilizados,. Dentro del esquema en que la burguesía se arroga el poder de tomar a su cargo la organización de la política, la economía, la justicia y la cultura y se considera la protagonista principal del progreso indefinido y el completo bienestar, el proletariado se convierte en "una clase condenada a soportar todos los inconvenientes de la sociedad sin gozar de sus ventajas, que se ve expulsada de la sociedad y obligada a colocarse en la más resuelta contraposición a todas las demás clases". ${ }^{14}$ Los obreros representan una instancia menor tanto en el rol que desempeñan como en sus aspiraciones, quedan ajenos o retrasados respecto del destino de Europa, carecen de las cualidades que enaltecen los discursos y formas de vida decimonónicas; los panegíricos del progreso llegan hasta sus oídos pero no hasta sus vidas, su función consiste se reduce a proveer fuerza de trabajo y ser fuente de mano de obra renovable.

Es interesante señalar el doble movimiento de la otredad implicado en lo expuesto sobre el mundo social y laboral en Marx. Por un lado, los obreros se convierten de hecho, independientemente de la conciencia de ello, en lo otro, lo opuesto, la contracara, del mundo burgués y los discursos apologéticos que éste enarbola. Por el otro, el fenómeno de la alienación lleva a considerar como otro a lo que en realidad no debería serlo: a sí mismo, a quienes comparten sus condiciones de clase y a sus congéneres; los

\footnotetext{
${ }^{12}$ El trabajo es un sacrificio de sí, una mortificación necesaria del cuerpo y el espíritu, adquiere un carácter exterior, el obrero no lo entiende como algo específico de su género, por ende, en el trabajo no se pertenece a si mismo, sino que pertenece a otro. El trabajo jamás es entendido como manifestación de la personalidad sino como medio de subsistencia dirigido a la ganancia. Hay una inversión entre la parte humana y las funciones propiamente animales: "el hombre (el trabajador) sólo se siente libre en sus funciones animales, en el comer, beber, engendrar, (...) y en cambio en sus funciones humanas se siente como animal. Lo animal se convierte en lo humano y lo humano en animal. Comer, beber y engendrar, etc., son realmente también auténticas funciones humanas. Pero en la abstracción que las separa del ámbito restante de la actividad humana y las convierte en fin único y último, son animales" [Manuscritos: economía y filosofía. Op. cit., pp. 112-3].

${ }^{13}$ Alienación proviene del vocablo latín alienus, que significa ajeno. De allí que en su raíz etimológica alienado y enajenado estén estrechamente unidos y suelan usarse como sinónimos. Marx emplea con frecuencia los términos alemanes Entfremdung y Entäusserung para mencionar este fenómeno y en ellos se encierran las notas nombradas: Entfremdung refiere a la acción por la que algo se vuelve extraño (fremd es extraño, ajeno y entfremden el verbo extrañar, enajenar), en tanto que Entäusserung hace hincapié en el hecho del desposeimiento, en la pérdida de algo que era propio, íntimo.

${ }^{14}$ Marx, Karl y Engels, Friedrich. La ideología alemana. Trad. Wenceslao Roces. Santiago Rueda Editores, Bs. As., 2005, p. 81.
} 
vive como extraños, hostiles, verdaderos otros desconocidos que están al acecho y son vividos como peligro más que como posibilidad.

Si bien es notoria esta condición impugnadora del proletariado en el sentido expuesto, Marx plantea que la clase trabajadora no puede tomar conciencia de ello y, por ende, tampoco pensar y actuar como un otro, debido a que "la clase que tiene a su disposición los medios para la producción material dispone con ello, al mismo tiempo, de los medios para la producción espiritual, lo que hace que se le sometan (...) las ideas de quienes carecen de los medios necesarios para producir espiritualmente. Las ideas dominantes no son otra cosa que la expresión ideal de las relaciones materiales dominantes". ${ }^{15}$ Las expresiones intelectuales y culturales son el reflejo de los intereses de una clase concreta, la burguesía, que las presenta como manifestaciones e intereses universales. Por ello es importante la tarea que le puede caber a la filosofía en el desenmascaramiento del carácter engañoso de las ideas y creencias prevalecientes en cada época, aunque con esta visión Marx se aparta de la concepción y función que tradicionalmente se le atribuyeron a la filosofía.

\subsection{Otredad filosófica: ideología y praxis}

La propuesta filosófica de Marx puede entenderse como una otredad opuesta a las líneas filosóficas dominantes en su época, representadas principalmente por el idealismo alemán en la primera mitad del siglo XIX y el positivismo en la segunda mitad de dicha centuria.

La principal crítica que realiza Marx a la concepción idealista neohegeliana es que ésta se origina en las ideas o representaciones que el hombre realiza, para luego tratar de explicar la realidad humana basándose en y sujetándose sólo a ellas; conducta que resume en la metáfora de que dicha filosofía "desciende del cielo sobre la tierra". ${ }^{16} \mathrm{El}$ cielo es identificado con las nociones idealistas en un doble sentido, primero por su distanciamiento de la tierra -y, por ende, de la realidad del hombre- y segundo por sus falaces presunciones de pureza -ilusión de ser abstracción total, verdadera, incontaminada-. Para Marx se debe proceder en sentido inverso, partir de la vida real para explicar los pensamientos. Las producciones y las relaciones materiales son el sustento de toda elaboración teórica y, por lo tanto, plantear la independencia del pensamiento respecto de la vida "terrenal" es simplemente una pretensión maliciosa o, cuando menos, errónea. Toda producción teórica o representación que se hace del mundo surge del modo en que se llevan adelante las actividades materiales y las relaciones que se establecen en ellas, por lo que éstas deben tenerse en cuenta en primer lugar al momento de iniciar cualquier elaboración filosófica. La filosofía no comienza por los conceptos universales o la identificación de principios abstractos, sino por las relaciones materiales de producción, a partir de las cuales se conforman los conceptos, categorías y representaciones en los que se desarrollan nuestras vidas; en la filosofía por la que aboga Marx "no se parte de lo que los hombres dicen, se representan o imaginan, ni tampoco del hombre predicado, pensado, representado o imaginado, para llegar, arrancando de aquí, al hombre de carne y hueso; se parte del hombre que realmente actúa y, arrancando de su proceso de vida real, se expone también el desarrollo de los reflejos ideológicos y de los ecos de este

\footnotetext{
${ }^{15}$ Ibíd. p. 50

${ }^{16}$ Ibíd. p. 26.
} 
proceso de vida. (...) Terminan allí las frases sobre la conciencia y pasa a ocupar su sitio el saber real". ${ }^{17}$

Otra crítica que realiza Marx a los que defienden una filosofía neutra -dentro de quienes ubica expresamente a los jóvenes neohegelianos, por ser con quienes discute en ese momento, pero también podría incluirse al positivismo- es la de desempeñarse como ideólogos. Marx denomina ideólogos a aquellos que sostienen que los conceptos provienen de un plano en donde no intervienen los intereses económicos o políticos, sólo las abstracciones puras, y colocan al pensamiento como motor de la historia, desconociendo que las relaciones materiales de los hombres son las que evolucionan, y gracias a éstas, progresan las ideas. Esta tarea de ocultamiento del origen de los conceptos hegemónicos y de generación de la falsa conciencia es la misión principal de los ideólogos. La falsa conciencia está en relación con el mecanismo mediante el cual se legitiman las formas de conocimiento y poder que rigen la conducta práctica de los individuos. La vida cotidiana de los integrantes de una sociedad se guía de acuerdo con los parámetros de la clase social que posee los medios de producción material y tiene una cierta concepción sobre el universo y la sociedad; a través de la falsa conciencia se realiza el encubrimiento del hecho que los conceptos no adquieren su fuerza sólo por cuestiones inherentes a ellos mismos, sino también y fundamentalmente porque están sostenidos por la clase dominante, la forma de ver la realidad e ideas de esta última, que son simplemente una justificación de su modo de producción, se imponen como verdades eternas, indiscutibles, razonablemente válidas para las clases dominadas.

Según Marx se pueden enfrentar las concepciones defendidas por los ideólogos, que niegan el origen real-material del que provienen las ideas y lo sitúan en el plano abstracto de los conceptos atemporales, de dos maneras diferentes. Primero, en el plano teórico, mostrando cuáles han sido las circunstancias materiales que provocaron su concepción y, por ende, refutando su supuesta pureza. En segundo lugar, y más importante aún, en el plano material, modificando las circunstancias en las que viven los hombres $\mathrm{y}$, en consecuencia, todo lo que pueda darse en el plano teórico en general a partir de ellas. ${ }^{18}$ Ambas formas deben estar en estrecha relación porque la misma actividad cognoscitiva es ya una actividad práctica, histórico-social y objetivante, no abstracta, contemplativa ni aislada; de aquí su crítica al materialismo de Feuerbach: "la falla fundamental de todo el materialismo precedente (...) reside en que sólo capta la cosa (Gegenstand), la realidad, lo sensible, bajo la forma del objeto (Objekt) o de la contemplación (Anschauung), no como actividad humana sensorial, como práctica". ${ }^{19}$ Esto trae consecuencias significativas para la actividad filosófica, ya que implica que su objetivo no sea puramente teórico, explicando o interpretando los hechos desde el plano del pensamiento, sino también práctico, ya que al filósofo le correspondería intervenir en la realidad social para modificarla desde el plano de la acción; expresión de esto es la archidifundida tesis XI: "los filósofos se han limitado a interpretar el mundo de distintos modos; de lo que se trata es de transformarlo". ${ }^{20}$

\footnotetext{
${ }^{17}$ Ibíd. pp. 26-7.

${ }^{18}$ Esta visión está expuesta en la mayoría de los textos del joven Marx, desde una forma más cruda con sesgos de vanguardia iluminada en Crítica de la filosofía del derecho de Hegel hasta versiones más elaboradas en La ideología alemana y la Contribución a la crítica de la economía política.

${ }^{19}$ Marx, Karl. Tesis sobre Feuerbach. Trad. Wenceslao Roces. En: La cuestión judía (y otros escritos). Selecc. e introd. José Bermudo, trad. varios. Planeta-Agostini, Barcelona, 1994, p. 229 (tesis I)

${ }^{20}$ Ibíd. p. 232 (tesis XI). Debido a que esta célebre frase ha sido comprendida de muy diversas maneras, consideramos apropiado detenernos a señalar que la interpretación hace alusión a los planteos filosóficos que actúan por omisión (aceptando, legitimando, etc.), en tanto que la transformación implica elaborar
} 
En cuanto a la oposición al positivismo, con el cual tiene en común el sustrato provisto por el realismo empírico-científico, Marx no comparte principalmente la defensa que éste hace de la posible neutralidad del conocimiento, pues soslaya el carácter ideológico de todo proceso cognitivo (que ya hemos desarrollado), y el profundo optimismo con que esta corriente analiza el desarrollo de la sociedad industrial. En este último aspecto, contra las loas que los positivistas lanzan a la sociedad erigida por el industrialismo científico-técnico y el capitalismo liberal, pues ven en esta formación social la gradual solución a los diferentes problemas de la humanidad y el punto máximo de civilización, ${ }^{21}$ Marx, muy por el contrario, reconoce en ella sólo una renovada forma de explotación y deshumanización y augura que la perversidad de las relaciones sociales que le es propia no conduce a las panaceas prometidas, sino sólo a aumentar los males existentes y los métodos represivos hasta el punto en que se convierta en inevitable la destrucción de las fuerzas productivas y el reemplazo del modo de producción.

En resumen, la actividad filosófica entendida al modo de Marx se aparta de la tradición filosófica nacida en la antigüedad y que continuaba siendo dominante en el tiempo en que vivió. Los planteos marxistas representan de algún modo una otredad, en el sentido de que ponen la filosofía en dependencia de los procesos sociales de producción y la sitúan en estrecha relación con la ideología y la praxis. Respecto de la ideología, la filosofía debe tomar en cuenta que en principio ella misma es ideología para poder luego avanzar más allá de lo que la producción espiritual de una cierta época determina como verdadero y, así, no quedar reducida meramente a ideología. En cuanto a la relación con la praxis, la actividad intelectual pierde el aura de impoluta y desinteresada ya que está imbricada desde sus inicios hasta el final con la praxis humana, tiene su origen y está orientada hacia esta última, no pueden separarse una de la otra.

\section{Nietzsche y la otredad}

Los planteos teóricos de Friedrich Nietzsche se enfrentan claramente con los paradigmas filosóficos dominantes en el siglo XIX ya que, a diferencia de lo propuesto por las corrientes idealistas y positivistas, sostiene la importancia y necesidad de prestar atención al cuerpo y el lenguaje como fuentes y ámbitos propios de la actividad filosófica. Asimismo ataca la concepción tradicional de razón, el modo en que se entiende el conocimiento y la búsqueda de verdades universales como objetivo último de éste.

En estos tópicos reside el núcleo de lo que puede ser considerado como otredad en Nietzsche. A continuación los desarrollamos agrupados en dos parágrafos, el primero dedicado a analizar la concepción de cuerpo y lenguaje nietzscheanos y el segundo en relación con su perspectivismo.

\subsection{Otredad de la razón: cuerpo y lenguaje}

Según Nietzsche el ser humano es un animal débil en comparación con los otros que habitan la tierra y utiliza el intelecto como medio de conservación. El intelecto de-

una interpretación que contemple y conlleve la praxis transformante. Interpretación es teoría que deja el mundo como está, que elabora sistema cerrados en sí mismos, que no tiende hacia la realidad y la sociedad, que no pasa de la crítica y que fragmenta al hombre; mientras que transformación es teoría que reconoce su imposible disociación de la praxis, su indisoluble unión con la acción. El pensamiento no se opone a la acción, ambos deben actuar en conjunto para invertir el estado dado según Marx.

${ }^{21}$ Cfr. principalmente de Auguste Comte: Curso de filosofía positiva. Trad. Carmen Lessining. Andrómeda, Bs. As., 2004 - Discurso sobre el espíritu positivo. Trad. Eugenio Moya. Biblioteca Nueva, Madrid, 1999. 
sarrolla sus tareas principalmente a través del arte de fingir (disimulo, encubrimiento, astucia, actuación, etc.), siendo este fingir el arma mediante la cual los seres humanos hacen frente a su debilidad constitutiva. El objetivo propio del razonar es la conservación de la vida del hombre y por ello se olvida de su carácter artificioso; debido a que el conocimiento tiene por principal misión lograr la supervivencia del individuo, no es posible que se tienda desinteresadamente hacia la verdad: "en los hombres alcanza su punto culminante este arte de fingir; aquí el engaño, la adulación, la mentira y el fraude, la murmuración, la farsa (...) es hasta tal punto regla y ley, que apenas hay nada tan inconcebible como el hecho de que haya podido surgir entre los hombres una inclinación sincera y pura hacia la verdad". ${ }^{22}$ La razón responde a necesidades concretas e inmediatas: las pasiones e instintos que constantemente luchan entre sí, en cada cuerpo. ${ }^{23}$

Los juicios tienen valor para la vida, sea para favorecerla, conservarla o inclusive seleccionarla, y es precisamente el instinto de vida lo que guía todo razonamiento. Pensamientos, valoraciones, conceptos son condiciones de vida y, en particular, de un determinado modo de vida, pero no son requisitos de un conocimiento necesario y verdadero. La verdad es simplemente una metáfora antropomorfizante más de las tantas que usamos los seres humanos en nuestra lucha por la supervivencia, metáfora de la que olvidamos su origen ilusorio y en la que se acumulan y condensan figuras retóricas de diferentes clases: “¿qué es entonces la verdad?. Una hueste en movimiento de metáforas, metonimias, antropomorfismos, en resumidas cuentas, una suma de relaciones humanas que han sido realzadas, extrapoladas y adornadas poética y retóricamente y que, después de un prolongado uso, un pueblo considera firmes, canónicas y vinculantes; las verdades son ilusiones de las que se ha olvidado que lo son; metáforas que se han vuelto gastadas y sin fuerza sensible". ${ }^{24}$

Solamente aquellas ilusiones que han servido para mantener la vida de manera práctica se convirtieron en verdades teóricas o morales. El compromiso que se genera a través de los hábitos sociales para el reconocimiento de determinadas metáforas como ciertas, y de otras como falsas, produce el olvido del génesis de dichas metáforas, permite la certeza inconsciente y, más importante aún, provoca el movimiento moral hacia la verdad: se la convierte en una instancia reguladora e imperativa mediante la cual el hombre que la enarbola se autoinstituye como un ser honesto y fiable y, en el mismo acto, se desase de quien sostiene metáforas opuestas, excluye al mentiroso.

Este impulso moral hacia la verdad confluye junto con el lenguaje en la tarea de generar las convenciones que sirven para uniformizar la heterogénea realidad. Según Nietzsche el hombre desea existir en sociedad de manera gregaria y para ello necesita una especie de tratado de paz, el cual instituye en primer lugar ciertas convenciones que aseguran que los integrantes de la sociedad posean representaciones equivalentes sobre la realidad y, por lo tanto, se conduzcan de manera similar ante ella y entre ellos: "este tratado de paz (...) fija lo que a partir de entonces ha de ser "verdad", es decir, se ha in-

\footnotetext{
${ }^{22}$ Nietzsche, Friedrich. Sobre verdad y mentira en sentido extramoral. Trad. Luis Valdés y Teresa Orduña, Madrid, Tecnos, 1998. pp. 18-9.

${ }^{23}$ Este cuerpo no es el cuerpo orgánico-físico de tejidos, humores y huesos que conforman al ser humano, sino que se define como un espacio conflictivo en donde numerosas fuerzas chocan entre sí y algunas terminan imponiéndose sobre las otras. El cuerpo es para Nietzsche el lugar de lo inconciente, de lo nonombrado, es el Sí-Mismo (Selbst) en contraposición con el Yo (Ich), en palabras de Zaratustra: "El cuerpo es una gran razón, una enorme multiplicidad dotada de un sentido propio, guerra y paz, rebaño y pastor" [Nietzsche, F. Así habló Zaratustra. Trad. Juan Carlos García Borrón. Planeta-De Agostini, Barcelona, 1992, p. 50].

${ }^{24}$ Nietzsche, Friedrich. Sobre verdad y mentira en sentido extramoral. Op. cit., p. 25.
} 
ventado una designación de las cosas uniformemente válida y obligatoria, y el poder legislativo del lenguaje proporciona también las primeras leyes de verdad, pues aquí se origina por primera vez el contraste entre verdad y mentira" ${ }^{25}$ El lenguaje aparece más como medio en el cual se cumple un contrato gramatical que permite a los hombres la convivencia pacífica que como una esfera independiente destinada a comunicar la esencia de las cosas y la verdad de los fenómenos reales. El lenguaje se erige de acuerdo con la voluntad y la pasión humana, está ligado desde sus principios con la satisfacción de necesidades prácticas y con las condiciones vitales de dominación propias del género humano, tiene un origen biológico, natural, es imposible que haya surgido de algún esfuerzo cultural individual o social, "el lenguaje es demasiado complicado para ser elaborado por un solo individuo; para serlo por la masa tiene demasiada unidad, es un organismo completo. Por tanto, no queda más remedio que considerar el lenguaje como producto del instinto, tal como sucede con las abejas, las hormigas, etc." ${ }^{26}$ La postura acerca de que es la racionalidad la que gobierna todo el andamiaje lingüístico es sólo una creencia infundada, es la manera en que se nos presentan de modo inofensivo -bajo el aspecto de la neutralidad- las fuerzas que han condensado en el lenguaje: "la dilucidación de las premisas básicas de la metafísica del lenguaje, esto es, de la razón, nos revela un tosco fetichismo". ${ }^{27}$

Nietzsche es contrario, por lo tanto, a una visión objetiva del lenguaje, se opone a considerarlo como un medio transparente de la razón que pueda comunicar significados independientes de él mismo o reflejar la realidad tal cual es. Es decir, se opone a la concepción especular del lenguaje predominante durante la modernidad y establece una clara división entre quienes sustentan una postura de este tipo y aquellos otros que ven en el lenguaje una esfera autónoma y opaca hasta cierto punto y que por ello requiere atención por sí misma: "el que encuentra el lenguaje interesante por sí mismo se distingue de quien no lo admite más que como medio [Médium] de pensamientos interesantes". ${ }^{28}$ El pensamiento de tipo abstracto y complejo característico de la raza humana sería imposible si no existiera una codificación y simbolización tal como la propia del lenguaje, éste es un elemento necesario para que se constituya el pensamiento racional; la razón no tiene prioridad sobre el lenguaje, no es el raciocinio lo que hace posible su surgimiento, sino que ambos se co-constituyen a partir de los principios fisiológicos o, invirtiendo la tesis clásica, es la idea de racionalidad la que se origina a través de los sistemas lingüísticos.

Fiel a su misión de filólogo, Nietzsche arremete contra la filosofía que quiere desentenderse de los problemas del lenguaje. Enérgico adversario de la metafísica, coloca al lenguaje en el centro de la escena y sostiene que es necesario prestarle atención

\footnotetext{
${ }^{25}$ Ibíd. p. 20. En la tarea de uniformizar la realidad cumplen una función importante los conceptos, pues ellos omiten lo individual y real y aferran nada más que la forma, forma que sólo puede ser instituida por la regularidad que aportan las categorías de conocimiento humanas.

${ }^{26}$ Nietzsche, Friedrich. El libro del filósofo. Retórica y lenguaje. Taurus, Madrid, 2000, p. 178. En el mismo libro sostiene que "no obstante el lenguaje no ha aparecido de repente, sino que es el resultado lógico de períodos infinitamente largos. Al llegar aquí se impone pensar en la génesis de los instintos: se desarrollan en términos absolutamente progresivos. La actividad espiritual de milenios condensada en el lenguaje" (p. 45). Y asimismo: "el lenguaje no es un producto [Werk] consciente, individual o colectivo" (p. 177).

${ }^{27}$ Nietzsche, Friedrich. El Anticristo. Cómo se filosofa a martillazos. Trad. Carlos Vergara. Edaf, Madrid, 1995. p. 134. Algunas oraciones después extiende un poco más la metáfora de la creencia en la racionalidad del lenguaje como una fe de tipo religioso al afirmar: "la razón en el lenguaje: ¡oh, qué mujer tan vieja y engañosa!. Temo que no nos libremos de Dios, por creer todavía en la gramática...”.

${ }^{28}$ Nietzsche, Friedrich. El libro del filósofo. Retórica y lenguaje. op.cit., p. 175.
} 
cuantas veces emprendamos el camino de la reflexión filosófica. La filosofía debe rastrear las condiciones en que se originaron los sentidos de las palabras y los conceptos, los cuales, luego de triunfar en varias batallas y de borrar las huellas de su origen agonístico, convirtieron a determinados símbolos en verdades irrecusables y en el sentido de la vida. En la definición del valor que se le otorga a ciertos conceptos (bueno, malo, obligatorio, pernicioso, etc.) se libra la lucha por el dominio y el poderío, en su Genealogía de la moral plantea que el campo de batalla donde los espíritus débiles vencieron a los fuertes fue justamente en el de los significados. La génesis de las palabras que ahora encarnan lo deseado, lo debido, está en las condiciones en que éstas surgieron, y ellas han emergido del odio, la inferioridad, el resentimiento y la necesidad de venganza que insuflaba el accionar de los seres endebles. El filósofo, en cuanto espíritu libre, debe acometer la misión de desenmascarar lo que está oculto detrás de los símbolos y, más importante aún, ser generador de nuevos sentidos que respeten y conecten con lo más propio de la vida humana, representado por las pulsiones corporales y de la tierra. ${ }^{29}$

\subsection{Otredad filosófica: perspectivismo}

La principal crítica que realiza Nietzsche a los filósofos recae sobre su falta de honestidad. Éstos se presentan a sí mismos como amantes de la sabiduría, buscadores de una verdad que no poseen y que, en consecuencia, es entendida de modo ajeno e independiente a ellos mismos; por lo que para alcanzarla plantean que deben ser dejados de lado sus odios, pasiones y temores, en definitiva, su vida instintiva y todo lo emergente del cuerpo. Considera que los filósofos han desarrollado su disciplina de manera dogmática, imponiendo ideas y disimulándolas como necesarias y universales pues no pueden vivir sin fijar conceptos a los cuales alabar y venerar como verdades absolutas con el fin de habitar y actuar con más tranquilidad en la realidad; han "compuesto un mundo en el que podemos vivir -mediante la aceptación de cuerpos, líneas, superficies, causas y efectos, movimiento y reposo, forma y contenido: ¡nadie resistiría hoy vivir sin estos artículos de fe! Pero no por eso ellos quedan demostrados. La vida no es un argumento; el error podría estar entre las condiciones de la vida". ${ }^{30}$

Los filósofos son falaces y carecen de honestidad porque no presentan su pensamiento como una forma de vida, como una costumbre, defecto o especificidad de la sociedad (de $s u$ tipo de sociedad), sino como la verdad; no como algo contingente, sino necesario; no como algo que emana de su mismo cuerpo, sino como algo proveniente de la realidad; no como algo inventado, sino encontrado. ${ }^{31}$ Los filósofos no son honrados

\footnotetext{
${ }^{29}$ Cfr.: Nietzsche, Friedrich. La genealogía de la moral. Trad. Andrés Sánchez Pascual. Alianza, Madrid, 2000. La posición privilegiada que otorga Nietzsche a los instintos y al lenguaje también queda evidenciada en que en su teorización acerca de la voluntad de poderío y la transvaloración considera como característica principal del hombre auténtico (el hombre noble, no el hombre del rebaño) el ser un creador permanente de sentido. El hombre fuerte es aquel que no acepta pasivamente lo que se le presenta como ya dado y se aferra a ello como su tabla de salvación, sino que es quien recrea de modo constante el sentido del mundo que lo rodea y los símbolos en que éste se expresa. El verdadero hombre comprende la contingencia de todas las construcciones humanas y la posibilidad, más bien necesidad, de que ellas sean superadas permanentemente.

${ }^{30}$ Nietzsche, Friedrich. La ciencia jovial. La gaya scienza. Trad. José Jara. Monte Ávila Editores, Venezuela, 1992, p. 112 (af. 121).

31 "Si alguien esconde una cosa detrás de un matorral, a continuación la busca en ese mismo sitio y, además, la encuentra, no hay mucho de qué vanagloriarse en esa búsqueda y ese descubrimiento; sin embargo, esto es lo que sucede con la búsqueda y descubrimiento de la verdad dentro del recinto de la razón”. Nietzsche, Friedrich. Sobre verdad y mentira en sentido extramoral. Op. cit., p. 28.
} 
porque ocultan el dogmatismo, la cobardía y el cansancio que los constituye e intentan imponer sus creencias como imparciales. Los conceptos, ideas o leyes que creen encontrar en la naturaleza de manera objetiva e independiente de las inclinaciones, según Nietzsche, no son otra cosa que los prejuicios condensados en el lenguaje y las características biológicas de las que están compuestos: "el hechizo de determinadas funciones gramaticales es, en definitiva, el hechizo de juicios de valor fisiológicos y de condiciones raciales". ${ }^{32}$

La imposibilidad de constatar la existencia de una significación natural, no impuesta, en los fenómenos (resumida en la famosa frase con que Nietzsche desfonda la realidad: "no hay hechos, sólo hay interpretaciones") y el carácter metafórico de la verdad conduce a que Nietzsche se oponga a cualquier visión correspondentista y a la búsqueda de un sentido originario en los hechos. Muy por el contrario, enarbola el perspectivismo como modo apropiado de abordar los sucesos. Para el perspectivismo nietzscheano ninguna visión de la realidad es mejor que otra por sí misma, sino que siempre depende de los intereses que persiguen quienes proponen y enuncian dicha perspectiva. Ante la condición ficcional del sentido y la verdad, no hay punto de vista que pueda poseer una relación privilegiada con la constitución del mundo o que responda de modo más fidedigno a lo que es la realidad. Las diferentes teorías en realidad están en lucha constante por imponerse unas sobre las otras, ser reconocidas como verdaderas es nada más que el modo en que los intereses de un determinado grupo triunfan sobre los demás.

Es infructuoso el procedimiento que tiene por objetivo encontrar el verdadero significado de los fenómenos -el sentido original con que se habrían dado-, la genealogía nietzscheana se afana por rastrear el derrotero que siguieron ciertas palabras y conceptos para adquirir el sentido y valor que poseen dentro de la civilización occidental, por captar su singularidad, por tratar de reconstruir su devenir y por registrar las luchas que han debido atravesar para llegar al presente, pero nunca para reconciliarlos con la historia o el saber. Por lo tanto, el perspectivismo y la genealogía nietzscheanos se contraponen a la búsqueda del origen como momento que enseña la verdadera comprensión, a las génesis lineales y al despliegue de explicaciones teleológicas de los conceptos; Foucault se encarga de precisar que el objetivo de nuestro autor, al bucear en el pasado, es precisamente el contrario: "la búsqueda de la procedencia no funda, al contrario, remueve aquello que se percibía inmóvil, fragmenta lo que se pensaba unido; muestra la heterogeneidad de aquello que se imaginaba conforme a sí mismo". ${ }^{33}$

Y la crítica del perspectivismo a la tradición filosófica no sólo se centra en la plurivalencia de la realidad, sino que también abarca la entidad sobre la que se fundamentaba toda la arquitectura del conocimiento: el sujeto. El sujeto moderno, representado paradigmáticamente por el modelo cartesiano de la "cosa pensante" (res cogitans), es una construcción ficticia de la que se ha valido la metafísica a los efectos de otorgar seguridad al hombre. Al pensamiento moderno, caracterizado por la transparencia de la conciencia y la luminosidad de la razón, Nietzsche enfrenta una concepción de sujeto basada en la primacía del cuerpo (Selbst) por sobre la racionalidad del entendimiento; la sustancialidad del sujeto autoconciente es disuelta por la nueva subjetividad nietzscheana basada en una pluralidad de relaciones de fuerza. Las fuerzas se relacionan entre sí azarosamente, lo que las mueve es la voluntad de poder -esa constante posibilidad de

\footnotetext{
${ }^{32}$ Nietzsche, Friedrich. Más allá del bien y del mal. Trad. Andrés Sánchez Pascual. Alianza, Madrid, 2000, p. 45.

${ }^{33}$ Foucault, Michel. Nietzsche, la genealogía, la historia. Trad. José Vázquez Pérez. Pre-textos, Valencia, 1997, p. 29.
} 
querer, de estar en tensión hacia algo-- ${ }^{34}$ una vez que entran en relación, las fuerzas no pueden más que expresar su cualidad, y dicha expresión configurará un cuerpo determinado. Así, el sujeto nietzscheano no coincide en nada con la res cogitans cartesiana, la subjetividad que propone no goza de la unidad y solidez que brinda el sentido del término cosa (res), que sigue siendo pensable en los términos de la sustancia aristotélica, sino que, más bien, fragmenta al sujeto en infinidad de sujetos-instintos que se relacionan entre sí en forma incierta. El sujeto nietzscheano queda configurado como resultado de las fuerzas que actúan en su seno y por la posibilidad que tienen esas fuerzas de expresarse.

El perspectivismo nietzscheano pretende, al fin y al cabo, desenmascarar los valores y principios que la tradición filosófica occidental ha erigido como los únicos aceptables y que permiten la continuidad y reproducción de un solo tipo de realidad y de subjetividad, evitando el surgimiento de otras realidades y subjetividades que desafíen las formas de conducta convenidas.

\section{Otredad en la filosofía de Marx y Nietzsche: consideraciones finales}

Consideramos que es apropiado tomar el concepto de otredad proveniente de la disciplina antropológica y aplicarlo al campo filosófico como estrategia para nuclear algunos de los principales componentes individuales, sociales y culturales que delimitaron y reestructuraron el concepto clásico de razón -eje rector de toda la tradición filosóficaen los dos últimos siglos. De modo análogo a como la antropología cultural debió reconocer la imposibilidad de despojarse de los condicionamientos sociales y culturales de cada época en su construcción de lo otro, la filosofía, a través de las transformaciones sufridas en la contemporaneidad, ha sido puesta en una situación donde debe admitir que interactúa y se conforma junto con su propia otredad, con mucho de aquello que históricamente había dejado de lado y calificado como inapropiado.

En lo que respecta específicamente a los dos autores tratados, tanto en Marx como en Nietzsche aparecen elementos teóricos que caben ser interpretados como forjadores de otredad. En Marx, la otredad social, representada por el proletariado, y la otredad filosófica, que propugna la inversión del sentido de la actividad filosófica, influyen recíprocamente entre sí: si la filosofía debe cambiar de finalidad es porque hay una realidad creada por el modo de producción capitalista que es inaceptable, y si hay una realidad económica que prevalece más allá de todas sus injusticias es porque los filósofosideólogos ayudan a legitimarla y desarrollarla; la sociedad industrial burguesa propugna a la vez que vuelve irrealizables los beneficios de la supuesta universalidad de la razón, por ello la filosofía tiene una misión transformadora que realizar. ${ }^{35}$ En tanto que en Nietzsche, la otredad filosófica, constituida por el carácter metafórico de la verdad y el

\footnotetext{
34 "La vida como la forma de ser conocida por nosotros es, específicamente, una voluntad de acumular fuerzas; todos los procesos de la vida tienen aquí su palanca: nada quiere conservarse, todo debe ser sumando y acumulado. La vida (...) tiende a un sentimiento máximo de poderío; es esencialmente un esfuerzo hacia un aumento de poderío; el esfuerzo no es otra cosa que un esfuerzo hacia el poder". Nietzsche, Friedrich. La voluntad de dominio. Trad. Eduardo Ovejero y Maury. Aguilar, Bs. As., 1951, p. 424.

${ }^{35}$ La contradicción entre el carácter universal otorgado a la razón y la atomización de los intereses de los diferentes grupos que integran la sociedad es bien señalada por Horkheimer: "las dificultades de la filosofía racionalista tienen su secreto origen en la circunstancia de que la universalidad que se atribuye a la razón no puede significar otra cosa que la concordancia de los intereses de todos los individuos, al tiempo que la sociedad sigue escindida en clases. Dado que la universalidad hipostatiza la concordancia de intereses en un mundo en el que todavía divergen irreconciliablemente, la apelación teórica a lo universal de la razón muestra siempre los rasgos de la falsedad, de la represión”. Horkheimer, Max. "Razón y autoconservación”. En: Teoría tradicional y teoría crítica. Trad. José Luis López. Paidós, Barcelona, 2000, p. 95.
} 
perspectivismo consecuente, remite ineludiblemente a la otredad de la razón, conformada por las fuerzas polivalentes del cuerpo y la lucha de sentidos del lenguaje; la racionalidad deja de ser el principio regulador de la vida y se configura nada más que como un conjunto de estrategias conceptuales para la conservación del poderío instintivo humano.

Por lo expuesto aquí queda demostrado que es posible aplicar con pertinencia el concepto de otredad a las elaboraciones teóricas de Marx y Nietzsche analizadas; a la vez, esta categoría puede servir como principio explicativo -uno entre varios otros másde las interrelaciones existentes entre las grandes transformaciones socio-políticas y las teórico-filosóficas acaecidas en el siglo XIX y, asimismo, puede ayudar a entender el proceso que desembocó en la notoria atomización y descentramiento característicos de la filosofía contemporánea. ${ }^{36} \mathrm{Si}$ bien la otredad en sentido amplio -todo aquello que no participa de los parámetros propios de la cultura o grupo social dominante- sin dudas está presente a lo largo de la historia de la filosofía, sea de modo expreso o implícito, consideramos que la otredad filosófica en el siglo XIX, a través de Marx y Nietzsche, toma un neto carácter impugnador de lo más acendrado de la tradición occidental, ya que ambos arremeten contra las características y potencialidades de la razón entendida en forma clásica, remarcan lo que ésta somete, niega o enjuicia como erróneo e irracional para constituirse como rectora de la vida y, desde sus respectivas perspectivas, delimitan y reestructuran el concepto de racionalidad moderna. ${ }^{37}$

Este movimiento de ruptura iniciado por nuestros autores, consistente en enarbolar nociones y entidades que se articulan con pautas filosóficas y culturales disímiles a las tradicionales, se ve reforzado y adquiere status propio a partir del siglo XX, lo que queda de manifiesto en la proliferación de herramientas conceptuales que tienden a criticar la filosofía de la conciencia, el uso de criterios universales y categorías metafísicas y promueven el reconocimiento de desarrollos teóricos contextualizados y relacionados con las prácticas sociales, lingüísticas, laborales y de disciplinamiento corporal.

\footnotetext{
ABSTRACT

El presente artículo toma el concepto de otredad proveniente de la antropología cultural e intenta aplicarlo a la producción de Karl Marx y Friedrich Nietzsche, con el propósito de profundizar su condición de "maestros de la sospecha” y precisar cuáles son los elementos

${ }^{36}$ En estos procesos es indudable el papel que cumplen las condiciones históricas del siglo XIX, aunque lo hacen en un sentido diferente que en el campo antropológico: la otredad antropológica se va forjando por el descubrimiento y relación con culturas muy diferentes a civilización europea, mientras que la otredad filosófica está más emparentada con las condiciones generadas puertas adentro por el desarrollo de la sociedad industrial, de las que Marx fue un atento escudriñador y Nietzsche un puntual anunciador de sus consecuencias.

${ }^{37}$ Viene bien aquí señalar que Foucault, en ¿Qué es la Ilustración?, asocia el discurso filosófico de la modernidad con la necesidad de reflexionar sobre el nosotros cultural: "para el filósofo plantear la cuestión de su pertenencia al presente ya no será de ninguna manera la cuestión de su pertenencia a una doctrina o a una tradición; (...) sino la de su pertenencia a cierto "nosotros", a un nosotros que se remite a un conjunto cultural característico de su propia actualidad” [Foucault, Michel. ¿Qué es la Ilustración?. Trad. Silvio Matonni. La Piqueta, Madrid, 1996, p. 70]. Precisamente esta característica de reflexionar sobre qué constituye lo específico de la cultura europea es lo que comienza a cambiar con Marx y Nietzsche, quienes invierten la dirección de la indagación, abandonan la búsqueda de lo más propio e intentan y se devanan por mostrar las partes constitutivas que conforman negativamente y dan fuerza en forma oculta al desarrollo del nosotros de la sociedad occidental.
} 
presentes en sus teorías que resultan impugnadores de la tradición filosófica y las estructuras sociales occidentales decimonónicas. Con tal objetivo, se realiza una exposición sintética de la noción de otredad y de las condiciones del contexto social y filosófico del XIX y luego se analizan los conceptos de Marx y Nietzsche que puedan relacionarse con la temática de la otredad.

This paper takes the concept of Otherness, that proceeds from the field of Cultural Anthropology, and tries to carry it to the works of Karl Marx and Friedrich Nietzsche. The main purposes are to go deep into their condition of "masters of suspicion" and to determine which elements of their theories go against philosophical tradition and social structures of XIX century. Taking this objective into account, we explain briefly the concept of Otherness and social and philosophical conditions of XIX century and then we analyze Marx and Nietzsche's ideas that could be in relationship with Otherness. 